\title{
A BSC method for supplier selection strategy using TOPSIS and VIKOR: A case study of part maker industry
}

\author{
Adel Azar ${ }^{a^{*}}$, Laya Olfat ${ }^{\mathrm{b}}$, Farzaneh Khosravani ${ }^{\mathrm{a}}$ and Reza Jalali ${ }^{\mathrm{b}}$
}

${ }^{a}$ Department of Management, Tarbiat Modarres University, Tehran, Iran

${ }^{b}$ Department of Management, Allameh Tabatabaei University, Tehran, Iran

AR T I C LE I NF O $\quad$ A B S TRACT

Article history:

Received March 30, 2011

Received in Revised form

May, 15, 2011

Accepted 15 May 2011

Available online

16 May 2011

Keywords:

Supply chain

BSC

Multi-objective decision making

techniques

Factor analysis

Goal programming

\begin{abstract}
In recent decades, provision-chain management has been one of the major concepts. The main reason that attracts attention to the concept is the increase in competition and struggle for the survival. There are different ways to increase the competition in organizations such as increasing productivity by acquiring information technology.

In this paper, we present an integrated model with the balanced score card framework for supplier selection strategy. The proposed model of this paper gathers 161 important factors suggested in the literature and selects the six most important ones using different multi criteria techniques. We also propose a goal programming techniques with some hard constraints and implement the mathematical model for real-world case study of auto industry. The proposed model is solved in four different forms using TOPSIS, VIKOR and the combination of these 2 factors with factor analysis. The preliminary results indicate that a combination of VIKOR and factor analysis presented better results with $9 \%$ reduction in costs, $38 \%$ increase of quality, and $3.2 \%$ increase in acceptability.
\end{abstract}

(C) 2011 Growing Science Ltd. All rights reserved.

\section{Introduction}

Competition is a well-known concept in the present complicated world. There are some necessary factors for any product or service to survive. There are different was to increase competition such as cost reduction programs, better customer services, increase in quality of products, etc. Supply chain management (SCM), as a tool, is one of the most important techniques to join different product components in a system from the raw materials stage to final production delivery stage. A good SCM program plays an important role in product development for any organization. One of the necessary steps on having a good SCM plan is to choose appropriate suppliers (Dulmin \& Mininno, 2009). There are normally different criteria involved for choosing appropriate suppliers, which make decision-making problem so complicated. On the other hand, traditional cost related items are also insufficient for decision-making problems. During the recent decade, decrease in product life cycle, globalization of product market and high celerity of technical skills development creates motivation for product promotion. Severe pressure in competition, has forced the companies to adopt strategies

\footnotetext{
* Corresponding author. Tel. +989121338591

E-mail addresses: azara@modares.ac.ir (A. Azar) 
to reduce costs and time from the stages of supply chain. In such a competitive atmosphere, provision plays a crucial role. The suppliers have direct and crucial effects on costs, quality, technology and the time spent to deliver the product to the market. In this discussion, there are two significant views:

-Without any doubt, the main aspect of ordering is to establish strong relationships with some suppliers in order to reduce production costs and to maintain quality standards and to the customers.

-In decision making for ordering, there's a need for a systematic approach in which suppliers are recognized.

The main questions associated with SCM plan are to find out the order quantity and the appropriate suppliers. When the SCM plan is made we face with two types of systems of mono and multi product ordering. According to the first system, all of the suppliers pay close attention to the customer's order quantity, quality and on time delivery of goods. As a result, the only problem here is to know the best supplier. Based on the second system, the kind of service is non-obligatory, which means the supplier is not responsible for the product (price, quantity, delivery, discount, etc) and it depends on other strategies to maintain the competing market. In this paper, we present a balanced score card (BSC) (Kaplan \& Norton, 1992) technique to chose appropriate supplier and implement our method for a case study of real-world problem. In BSC we consider non-financial elements along with financial figures to provide a better picture of decision making. The remaining of this paper is organized as follows. We first present the literature review in section 2. In section 3, we present the proposed model of this paper along with the details of our computations. Finally, concluding remarks are given in the last to summarize the contribution of the paper.

\section{Literature Review}

BSC was first developed in early 90s in Nolan Norton Institution (Kaplan \& Norton, 1996). The method has been widely used in different works (Lamotte \& Carter, 2000; Anderson et al., 2000; Wongrassamee et al., 2003). BSC provides comprehensive and quick insight of business to the managers. According to BSC technique, there is a fact that companies would not be able to maintain their competitive advantages by only establishing a developing objective finances. In better words, "invisible finances" or "Mental capital" would be the crucial factor for success to establish and preserve the competitive advantage (Sime \& Koh, 2001, p11).

BSC includes financial criteria, which indicates previous activities' results, and also includes operational criteria associated with customer satisfaction, internal processes, creativity and learning. Such criteria are the incentives to financial functions in the future (Kaplan \& Norton, 1992, p6). BSC also indicates some aspects of promotion and "invisible finances" (Sim \& Koh, 2001, p8). Thus, the inefficiencies in traditional evaluating systems may be concealed by making values of "invisible finances" (Decoene \& Gruggeman, 2006).

There is no doubt that the most important decisions in shopping are choosing and maintaining close relationships with a small number of trustworthy suppliers, which reduces product casts while preserving its quality after sale. Therefore, systematic approach would contribute to decision making to recognize appropriate suppliers.

The critical characteristics must be taken into account while we decide to choose a supplier (Aissaoui $\&$ et al., 2006). Chen and Lin (2004) introduced a holistic insight of literature and determined 183 characteristics for evaluating suppliers. These characteristics were classified into 8 aspects: 1) financial, 2) man source management, 3) industrial traits, 4) Knowledge management, 5) marketing, 6) compatibility, 7) product promotion and logistics management, 8) establishment and coordination of relationships (Chen \& Lin, 2004). More than 50 percent of evaluations characteristic were based on two last items. Marvin et al. (2004) investigated the significance of supplier selection process in production, and looked for quality improvement in production process (Marvin et al., 2004). Razmi, et al. (2008) exploited a multi criteria decision making technique called TOPSIS and its combination with linear planning for choosing a supplier (Razmi et al., 2008). Mikhailov (2002) represented phase approach for choosing a supplier in virtual organizations (Mikhailov, 2002). He developed a technique, hierarchical analysis process (AHP), using staged data. Chen \& Lin (2004) manipulated 
phase decision making frame for choosing a convenient supplier (Chen \& Lin, 2004). Some of the newest studies about and criteria for choosing a supplier are summarized in Table 1.

\section{Table1}

Studies and criteria used for choosing a supplier

\begin{tabular}{|c|c|}
\hline Research and Researcher & Utilized Criteria \\
\hline Wang, W. P., 2010 & $\begin{array}{l}\text { Quality, Performance, and Technology level, Ability to supply all the orders, Time ordering cycle, On } \\
\text { time delivery, Ability to supply urgent orders, Precise documentation, Discounts, Price, Performance, } \\
\text { cost reduction, financial abilities, Sale post services, Ease of communication, Ability and desire to } \\
\text { participate in design processing, Back up and Coordination, Guarantee and warranty }\end{array}$ \\
\hline Kesking et al., 2010 & $\begin{array}{l}\text { Equipment, Adequate staff, Safe production, Sufficient producing capacity, Evaluation and control } \\
\text { systems, Design and improvement ability, Financial commitments, Price, Packing, Transportation, } \\
\text { Location, Environmental effects and preventive abilities, Safety, World class Manufacturing }\end{array}$ \\
\hline Sawik, 2010 & $\begin{array}{l}\text { Supplier capacity, Ordering cost, Price, Growth rate, Failure rate, Delay on delivery rate, Purchasing } \\
\text { amount, Waste cost }\end{array}$ \\
\hline Ustun \& Demirtas (2008) & Profit (quality and services), Costs, Opportunities, Risks \\
\hline Ha \& Krishnan, 2008 & Pleasure, Flexibility, Risk, Trust \\
\hline (2010) Lam et al., 2010 & $\begin{array}{l}\text { Cost: Total cost, Price stability, Quality: Failure prevention cost, Evaluation activities, Quality Standards, } \\
\text { Service: On time delivery, Technical cooperation and support, Communication and coordination, Buyer } \\
\text { and supplier relationships: Costumers' Loyalty, Supplying guarantee, Abilities, Flexibilities and Trust, } \\
\text { Payment Principles, Performance history, Credibility }\end{array}$ \\
\hline Wu et al., 2009 & Managerial, Technical, Operational, Fixed cost, Valuable cost \\
\hline Liao \& Kao, 2010 & Quality, Price, Delivery, Services, Guarantee and warr \\
\hline Guo et al., 2009 & $\begin{array}{l}\text { Quality, Price, Guarantee, Delivery, Catalog, After sale services, technical support, Instruction helping, } \\
\text { Performance and Historical records, Ability in electronic commercials, Packing and Storing abilities, } \\
\text { Reworking amount, Mutual agreements, products design, Finance and location status, Responsiveness, } \\
\text { Operational Control, JT capabilities, Environmental performance, Credibility, Communication systems, } \\
\text { Production capabilities, Workforce relations, Technology and Innovation utilization }\end{array}$ \\
\hline Önüt et al., 2009 & $\begin{array}{l}\text { Costs, Supplier's credibility and background, product's quality, Delivery, Organizational conditions, } \\
\text { Coordination period }\end{array}$ \\
\hline $\begin{array}{l}\text { Hsu, C. W., \& Hu, A. H., } \\
2009\end{array}$ & Supplying management, R\&D, Management process, Quality control, System management \\
\hline Wu, D., 2009 & $\begin{array}{l}\text { Inputs (Quality management systems and activities, Inspection, Producing process improvement, } \\
\text { Management, R\&D, Cost reduction abilities), Outputs (Quality, Price, Delivery, Price reduction } \\
\text { performance) }\end{array}$ \\
\hline Guneri et al. 2009 & $\begin{array}{l}\text { Credibility and Position in industry, Performance history, Conflicts solution, Delivery, Close } \\
\text { relationships, Complaints handling }\end{array}$ \\
\hline Luo et a., 2009 & Managerial and technological capabilities, financial abilities, Resources available, Quality \\
\hline Shen \& Yu, 2009 & Time cycle, Communication, Organization, Services, Quality \\
\hline Lee, 2009 & $\begin{array}{l}\text { Opportunities (Enhancing shared opportunities and growing, technology), Risk (Supplier profile, } \\
\text { Supplier and buyer limitations, Industry limitations), Costs (Communication and advertisement Costs, } \\
\text { Production costs, Transportation costs), Profits (Delivery, Flexibility, Quality) }\end{array}$ \\
\hline
\end{tabular}

As mentioned before, in all past researches, choosing a supplier were based on restrained criteria, and therefore, it is necessary to represent a holistic model, which includes all significant aspects of choosing a supplier. In this model, BSC approach is used for such a purpose.

\section{The proposed BSC model}

In this paper, we first review all the existing criteria in the literature, discuss them in some brainstorming meeting, and then choose the most appropriate ones. For the literature review of our study, the following six factors have been chosen from 161 criteria for the case study of this paper, which is a major supplier of auto industry called Sapco.

1) Internal process

2) Product

3) Financial

4) Customer - market, social charge and relations with beneficiaries

5) Technology

6) Organizational, managerial and human sources. 
Then, phase supposition test it used to determine the accuracy level of a hypothesis. A hypothesis may include certain or phase (stated) data. A hypothesis test creates a value in $[0,1]$ range, that indicates the accuracy level of a null hypothesis and alternative hypothesis (for sample data). Phase supposition test confirms $\mathrm{H}_{0}$ hypothesis to the amount of $\mu$, and alternative hypotheses to $(1-\mu)$. In general phase, supposition test does not intend to accept or refute a hypothesis as a whole, but to point out the accuracy level of each hypothesis. Therefore, test hypotheses were edited based on 7item spectrum and for each of the proposed criteria. Accordingly, the criterion with a confirmation level more than 66.7 was chosen.

\subsection{Evaluation of weights for indices}

We need to know partial values of indexes in most of the multiple criteria decision making methods (MCDM) (Yoon \& Hwang, 1981). In this study, Entropy approach was applied to evaluate the existing indexes weights. Entropy is a major concept in physics, sociology and information theory so that it indicates the amount of existent uncertainty in. informational expected content of a message (Yoon \& Hwang, 1981). Criteria weights which were calculated using Entropy method are shown in Table 2.

Table 2

Final criterion for choosing Sapco supplier

\begin{tabular}{|c|c|c|c|}
\hline View & Confirmation Degree Weights of Criteria & & \\
\hline \multirow{4}{*}{ Internal Process } & $\begin{array}{l}\text { Supplier company's flexibility in changing the volume and date of delivery of the } \\
\text { demanded product }\end{array}$ & 0.74 & 0.0358 \\
\hline & Delay time of supplier company & 0.79 & 0.0299 \\
\hline & Past performance advantage of P.C & 0.73 & 0.0361 \\
\hline & The number of provided pieces by supplier & 0.68 & 0.0319 \\
\hline \multirow{5}{*}{ Financial } & Price Stability & 0.73 & 0.0358 \\
\hline & Sale percentage of IK & 0.69 & 0.0235 \\
\hline & Transportation cost of each unit & 0.7 & 0.0279 \\
\hline & The situation \& financial stability of the P.C & 0.69 & 0.0357 \\
\hline & Non-IK sale percentage & 0.74 & 0.0237 \\
\hline \multirow{4}{*}{$\begin{array}{l}\text { Product } \\
\text { R\&D }\end{array}$} & Ability to design pieces & 0.71 & 0.0365 \\
\hline & The time needed for producing new sample pieces & 0.65 & 0.0357 \\
\hline & Supplier's flexibility to new requests & 0.83 & 0.0356 \\
\hline & Reliability of pieces & 0.79 & 0.0359 \\
\hline \multirow{3}{*}{$\begin{array}{l}\text { Information } \\
\text { Technology }\end{array}$} & Satisfaction of users & 0.69 & 0.0362 \\
\hline & Users’ IT services coverage & 0.71 & .00761 \\
\hline & Information systems coverage with process & 0.71 & 0.0362 \\
\hline \multirow{6}{*}{$\begin{array}{l}\text { Social, } \\
\text { customer, and } \\
\text { market } \\
\text { responsibility }\end{array}$} & Pause cost & 0.69 & 0.0221 \\
\hline & Level of relation and cooperation of P.C and Sapco company & 0.69 & 0.0359 \\
\hline & PPM & 0.71 & 0.0232 \\
\hline & IK customer's satisfaction & 0.68 & 0.0355 \\
\hline & Non-IK customer satisfaction & 0.74 & 0.0359 \\
\hline & Reputation of P.C & 0.72 & 0.0359 \\
\hline \multirow{5}{*}{$\begin{array}{l}\text { Organizational, } \\
\text { Managerial and } \\
\text { Human } \\
\text { Resource }\end{array}$} & Strategic adaptability of P.C to Sapco company & 0.67 & 0.0358 \\
\hline & Organizational and managerial stability & 0.69 & 0.0357 \\
\hline & Coordination History & 0.78 & 0.0354 \\
\hline & Reputation of Supplier & 0.71 & 0.0352 \\
\hline & Organizational Commitment & 0.7 & 0.0359 \\
\hline
\end{tabular}

\subsection{Ranking Sapco suppliers using multi-criteria decision making methods}

There are different MCDM techniques for ranking different alternatives such as AHP, VIKOR and TOPSIS. The proposed model of this paper uses VIKOR and TOPSIS for the case study of our proposed model.

\subsubsection{Ranking by TOPSIS}

In this method, decision matrix is normalized by Euclidean norms and then they the normalized matrix is multiplied in weight to make weight normalized vector to compute positive and/or negative ideals. Next, the distances between the choices are calculated based on Euclidean method out of 
positive/negative ideals, and finally, the relative closeness of each choice to the ideal solution is computed.

\subsubsection{Ranking by VIKOR}

In this method, we form decision making matrix, linear decaling, the best and the worst quantities. In a $\mathrm{Q}$ group, the choice is selected as the best if it can satisfy two conditions:

A) Let $\mathrm{A}^{(1)}$ and $\mathrm{A}^{(2)}$ be the first and the second best choices, respectively associated with $\mathrm{Q}$ and $\mathrm{N}$ groups. The following relationship holds,

$$
Q\left(A^{(2)}\right)-Q\left(A^{(1)}\right) \geq \frac{1}{n-1}
$$

B) The choice, $\mathrm{A}^{(2)}$ must be recognized as the best choice in $\mathrm{R}$ or $\mathrm{S}$ groups.

When the first condition does not held, a set of choices are chosen as the best choices as follows:

The best choices - $\mathrm{A}^{(1)}, \mathrm{A}^{(2)}, \mathrm{A}^{(\mathrm{M})}$

The highest quantity of $\mathrm{M}$ is calculated as the following,

$Q\left(A^{(M)}\right)-Q\left(A^{(1)}\right)<\frac{1}{n-1}$.

When the second condition does not held, $\mathrm{A}^{(1)}$ and $\mathrm{A}^{(2)}$ are chosen as the best choices. Table3. Shows the ranking of supplier companies based on TOPSIS and VIKOR:

\section{Table 3}

Ranking of supplier companies based on TOPSIS and VIKOR

\begin{tabular}{|c|c|c|c|c|c|c|c|c|c|c|c|}
\hline \multirow[b]{2}{*}{ Supplier Name } & \multicolumn{4}{|c|}{ TOPSIS } & \multicolumn{7}{|c|}{ VIKOR } \\
\hline & $d^{+}$ & $d^{-}$ & $\mathrm{CL}$ & Rank & $\mathrm{S}$ & Rank & $\mathrm{R}$ & Rank & Q & Rank & $\begin{array}{l}\text { Final } \\
\text { Rank }\end{array}$ \\
\hline Vasegh Forj & 0.041 & 0.048 & 530.0 & 14 & 0.5055 & 16 & 0.0740 & 14 & 0.5908 & 13 & 13 \\
\hline Lola Khodro & 0.041 & 0.052 & 0.559 & 11 & 0.3899 & 7 & 0.1542 & 24 & 0.3432 & 3 & 3 \\
\hline $\begin{array}{l}\text { Peyvand Tose'e Automobile } \\
\text { Industry }\end{array}$ & 0.038 & 0.039 & 0.502 & 20 & 0.3887 & 6 & 0.0740 & 14 & 0.6861 & 19 & 19 \\
\hline Shayan Kav & 0.043 & 0.041 & 0.486 & 21 & 0.4902 & 12 & 0.0555 & 5 & 0.6822 & 18 & 18 \\
\hline Electronic Power Supplyer & 0.040 & 0.042 & 0.511 & 18 & 0.4385 & 9 & 0.1357 & 22 & 0.3825 & 6 & 6 \\
\hline Fara kloun & 0.029 & 0.055 & 0.651 & 2 & 0.1977 & 2 & 0.0382 & 3 & 0.9946 & 24 & 24 \\
\hline $\begin{array}{lll}\text { Couban } & \text { Mobaddel } & \text { Fard } \\
\text { Industry } & & \end{array}$ & 0.036 & 0.057 & 0.615 & 4 & 0.5166 & 17 & 0.0740 & 14 & 0.5818 & 12 & 12 \\
\hline Tehran Technique & 0.047 & 0.051 & 0.522 & 16 & 0.8107 & 24 & 0.0704 & 13 & 0.3573 & 4 & 4 \\
\hline Kosar Sanat Abzar & 0.041 & 0.045 & 0.522 & 15 & 0.1308 & 1 & 0.1419 & 23 & 0.1993 & 1 & 1 \\
\hline Saze Pouyesh & 0.025 & 0.057 & 0.698 & 1 & 0.2492 & 3 & 0.0591 & 6 & 0.8635 & 22 & 22 \\
\hline Tavana Nikan Ghaleb & 0.058 & 0.034 & 0.369 & 24 & 0.5880 & 19 & 0.1172 & 21 & 0.3395 & 2 & 2 \\
\hline Sadr Paydaar Industry & 0.038 & 0.054 & 0.0586 & 8 & 0.5012 & 13 & 0.0678 & 8 & 0.6206 & 16 & 16 \\
\hline Gharb Steel & 0.032 & 0.056 & 0.637 & 3 & 0.4685 & 10 & 0.0864 & 18 & 0.5684 & 11 & 11 \\
\hline Sim Goon & 0.047 & 0.048 & 0.505 & 19 & 0.7911 & 23 & 0.0740 & 14 & 0.3579 & 5 & 5 \\
\hline Shayan Clutch Industry & 0.035 & 0.050 & 0.587 & 7 & 0.3803 & 5 & 0.0370 & 2 & 0.8508 & 21 & 21 \\
\hline Fadak Raah Ghate'e & 0.039 & 0.049 & 0.558 & 12 & 0.4731 & 11 & 0.0678 & 8 & 0.6435 & 17 & 17 \\
\hline Automotive Parts Engineering & 0.044 & 0.046 & 0.514 & 17 & 0.3130 & 4 & 0.0369 & 1 & 0.9060 & 23 & 23 \\
\hline Omid Ettehade Part Molding & 0.037 & 0.048 & 0.568 & 9 & 0.5189 & 18 & 0.0678 & 8 & 0.6062 & 14 & 14 \\
\hline Gharb Arad Group of Industry & 0.038 & 0.054 & 0.589 & 6 & 0.6146 & 20 & 0.0987 & 20 & 0.3966 & 7 & 7 \\
\hline Avam Industry & 0.039 & 0.050 & 0.561 & 10 & 5020.0 & 14 & 0.0678 & 8 & 0.6200 & 15 & 15 \\
\hline Pars Ziba Faraz & 0.049 & 0.040 & 0.448 & 23 & 0.7341 & 22 & 0.0695 & 12 & 0.420 & 8 & 8 \\
\hline Oskoo Azar Industry & 0.045 & 0.043 & 0.484 & 22 & 0.7298 & 21 & 0.0668 & 7 & 0.4384 & 9 & 9 \\
\hline Toos Mahd Khodro & 0.034 & 0.051 & 0.600 & 5 & 0.4066 & 8 & 0.0431 & 4 & 0.8031 & 20 & 20 \\
\hline Qom Milad & 0.041 & 0.049 & 0.584 & 13 & 0.5025 & 15 & 0.0864 & 18 & 0.5407 & 10 & 10 \\
\hline
\end{tabular}

According to Table 3, Saze Pouyesh company receives the highest rank based on TOPSIS technique and Kosar Sanat Abzar receives the highest rank according to VIKOR technique.

\subsubsection{Supplier ranking by factor analysis composition and MCDM methods}

One of the primary assumptions on our methods is that all criteria are mutually excluded. This simple assumption may not always hold. In this study, the matter of cohesion among the indexes was 
excluded using factor analysis, and new independent factors were inserted in decision matrix as entries and ranking was done using multi-criterion methods.

The quantities associated with decision-making were indentified before factor analysis is implemented. In linear decaling the achieved quantities ranged between $0 \& 1$. This scale is linear, and makes all results equally linear; therefore, positions of the indexes and their results remain equal. The quantity of variance determined by initial variables, extractive components, and the item after rotation is shown in Table 4.

Table 4

The amount of variance, described by the factor before and after Rotation

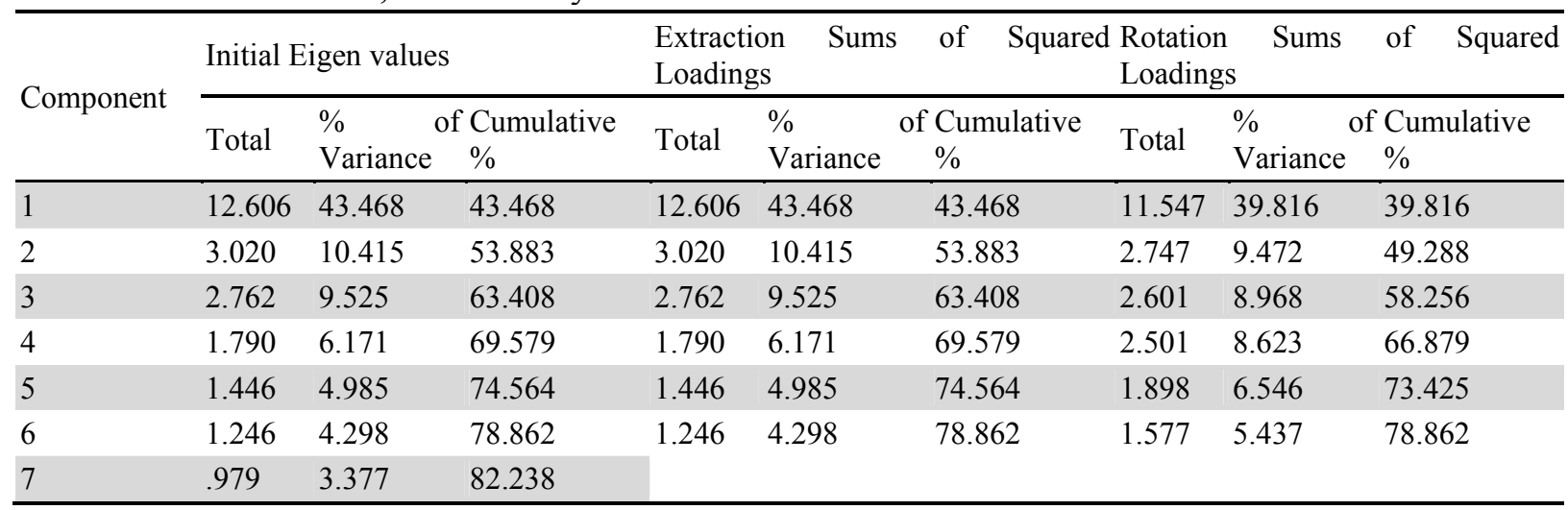

According to Table 4 the information of initial Eigen values, the extraction sums of squared loadings and the rotation sums of squared loadings are reported. As we can observe, the principle component analysis (PCA) could determine six factors with 0.7862 percent of the variance (Kline, 1993). Next, we need to recognize the relative importance of new factors for ranking supplier companies. The weights of new factors (indexes) are calculated as follows,

$W_{j}=\sqrt{\sum_{i=1}^{n} w_{i}\left(l_{i j}\right)^{2}}$

where $\mathrm{W}_{\mathrm{j}}$ is the weight of extractive factors using factor analysis and $\mathrm{w}_{\mathrm{i}}$ is the weight of index and $\mathrm{L}_{\mathrm{ij}}$ is the jth factor weight on ith index.

Having calculated $\mathrm{W}_{\mathrm{j}}$, the equated weight of the indexes is calculated as follows,

$\mathrm{w}_{\mathrm{j}}^{\prime}=\frac{\mathrm{w}_{\mathrm{j}}}{\sum_{\mathrm{j}=1}^{\mathrm{F}} \mathrm{w}_{\mathrm{j}}}$

Factor weights make the cohesion of the factors with variables (Kline, 1993). When the factors are independent, factor weights show variable dependency on the factors as well, and it is also used as a weight to predict the variable out of the factors (Kline, 1993).

Here, the roots of factor weights are used for evaluating the amount of dependency of factor on former indexes. Factor weights accord with Table 5.

Table 5

Recognized new factor weights

\begin{tabular}{lllllll}
\hline Factor & Factor 1 & Factor 2 & Factor 3 & Factor 4 & Factor 5 & Factor 6 \\
\hline Weight & 0.303 & 0.163 & 0.158 & 0.112 & 0.127 & 0.137 \\
\hline
\end{tabular}

The ranks of supplier companies are re-computed by VIKOR and TOPSIS techniques. Table 6 shows the ranks of supplier companies of Sapco: 
Table 6

Ranking of supplier companies based on factor analysis and multi-criterion decision techniques

\begin{tabular}{|c|c|c|c|c|c|c|c|c|c|c|c|}
\hline \multirow{2}{*}{ Supplier Name } & \multicolumn{4}{|c|}{ TOPSIS } & \multicolumn{7}{|c|}{ VIKOR } \\
\hline & $d^{+}$ & $d^{-}$ & $\mathbf{C L}$ & Rank & $\mathbf{S}$ & Rank & $\mathbf{R}$ & Rank & $\mathbf{Q}$ & Rank & $\begin{array}{l}\text { Final } \\
\text { Rank }\end{array}$ \\
\hline Vasegh Forj & 0.056 & 0.023 & 0.293 & 19 & 0.645 & 22 & 0.161 & 19 & 0.492 & 19 & 19 \\
\hline Lola Khodro & 0.056 & 0.044 & 0.442 & 13 & 0.627 & 19 & 0.157 & 17 & 0.457 & 17 & 17 \\
\hline $\begin{array}{l}\text { Peyvand Tose'e Automobile } \\
\text { Industry }\end{array}$ & 0.035 & 0.045 & 0.560 & 10 & 0.511 & 11 & 0.124 & 9 & 0.267 & 9 & 9 \\
\hline Shayan Kav & 0.054 & 0.032 & 0.373 & 16 & 0.609 & 17 & 0.116 & 13 & 0.355 & 13 & 13 \\
\hline Electronic Power Supplyer & 0.052 & 0.040 & 0.438 & 15 & 0.585 & 15 & 0.149 & 15 & 0.402 & 15 & 15 \\
\hline Fara kloun & 0.023 & 0.090 & 0.797 & 1 & 0.319 & 1 & 0.124 & 1 & 0.050 & 1 & 1 \\
\hline Couban Mobaddel Fard Industry & 0.041 & 0.067 & 0.622 & 6 & 0.477 & 8 & 0.137 & 8 & 0.258 & 8 & 8 \\
\hline Tehran Technique & 0.069 & 0.023 & 0.253 & 21 & 0.626 & 18 & 0.267 & 23 & 0.704 & 23 & 23 \\
\hline Kosar Sanat Abzar & 0.071 & 0.014 & 0.167 & 23 & 0.734 & 24 & 0.184 & 20 & 0.640 & 20 & 20 \\
\hline Saze Pouyesh & 0.023 & 0.080 & 0.776 & 2 & 0.539 & 2 & 0.119 & 2 & 0.099 & 2 & 2 \\
\hline Tavana Nikan Ghaleb & 0.049 & 0.029 & 0.368 & 17 & 0.606 & 16 & 0.134 & 14 & 0.392 & 14 & 14 \\
\hline Sadr Paydaar Industry & 0.032 & 0.046 & 0.590 & 9 & 0.486 & 9 & 0.098 & 7 & 0.182 & 7 & 7 \\
\hline Gharb Steel & 0.049 & 0.038 & 0.438 & 14 & 0.582 & 14 & 0.154 & 16 & 0.410 & 16 & 16 \\
\hline Sim Goon & 0.088 & 0.016 & 0.152 & 24 & 0.716 & 23 & 0.303 & 24 & 0.881 & 24 & 24 \\
\hline Shayan Clutch Industry & 0.042 & 0.037 & 0.471 & 12 & 0.527 & 12 & 0.136 & 11 & 0.311 & 11 & 11 \\
\hline Fadak Raah Ghate'e & 0.026 & 0.057 & 0.689 & 3 & 0.425 & 4 & 0.101 & 3 & 0.122 & 3 & 3 \\
\hline Automotive Parts Engineering & 0.039 & 0.042 & 0.522 & 11 & 0.509 & 10 & 0.149 & 12 & 0.319 & 12 & 12 \\
\hline Omid Ettehade Part Molding & 0.027 & 0.049 & 0.646 & 4 & 0.432 & 5 & 0.107 & 5 & 0.145 & 5 & 5 \\
\hline Gharb Arad Group of Industry & 0.036 & 0.056 & 0.611 & 8 & 0.445 & 6 & 0.158 & 10 & 0.270 & 10 & 10 \\
\hline Avam Industry & 0.029 & 0.046 & 0.618 & 7 & 0.450 & 7 & 0.097 & 4 & 0.143 & 4 & 4 \\
\hline Pars Ziba Faraz & 0.064 & 0.019 & 0.228 & 22 & 0.634 & 21 & 0.245 & 21 & 0.665 & 21 & 21 \\
\hline Oskoo Azar Industry & 0.066 & 0.026 & 0.285 & 20 & 0.579 & 13 & 0.276 & 22 & 0.673 & 22 & 22 \\
\hline Toos Mahd Khodro & 0.030 & 0.050 & 0.623 & 5 & 0.424 & 3 & 0.122 & 6 & 0.168 & 6 & 6 \\
\hline Qom Milad & 0.056 & 0.025 & 0.312 & 18 & 0.627 & 20 & 0.165 & 18 & 0.482 & 18 & 18 \\
\hline
\end{tabular}

According to the Table 6 Fara kloun company receives the highest rank based on VIKOR and TOPSIS techniques. Since there are differences between the ranking of various methods we perform Spearman test to study four methods used in this study. Table 7 summarizes the results of our Spearman test.

Table 7

Spearman's ranking interdependency coefficient for supplier companies in any of the ranking methods

\begin{tabular}{lllllll}
\hline & & & TOPSIS & VIKOR & PCA-TOPSIS & PCA-VIKOR \\
\hline Spearman's rho & TOPSIS & Correlation Coefficient & 1.000 & $-.431^{*}$ & $.711^{* *}$ & $.625^{* *}$ \\
& & Sig. (2-tailed) &. & .035 & .000 & .001 \\
& \multirow{2}{*}{ VIKOR } & Correlation Coefficient & $-.431^{*}$ & 1.000 & $-.685^{* *}$ & $-.714^{* *}$ \\
& & Sig. (2-tailed) & .035 &. & .000 & .000 \\
& PCA- & Correlation Coefficient & $.711^{* *}$ & $-.685^{* *}$ & 1.000 & $.964^{* *}$ \\
& TOPSIS & Sig. (2-tailed) & .000 & .000 &. & .000 \\
& PCA- & Correlation Coefficient & $.625^{* *}$ & $-.714^{* *}$ & $.964^{* *}$ & 1.000 \\
& VIKOR & Sig. (2-tailed) & .001 & .000 & .000 &. \\
\hline
\end{tabular}

*. Correlation is significant at the 0.05 level (2-tailed)

**. Correlation is significant at the 0.01 level (2-tailed)

The results show a close relationship in TOSIS method results with and without factor analysis. Similarly, TOSIS and VIKOR showed a high level of relationship, and their results are very similar.

\subsubsection{Accumulated amount determination for allocation to each supplier (Goal programming model)}

In this stage, with regard to the goals, parameters limitations, and also expressed suppositions, we propose a model to determine the amount of order allocated to each supplier. 


\subsubsection{Goal constraints}

There are different criteria to be chosen for order allocation to suppliers. In this study, we choose the first set of goals as reducing purchase costs, which includes purchase and transportation costs and optimizing the quality of the purchased item. The second goal is "reducing the number of rejected items. Let $x_{i j}$ and $p_{i j}$ be the amount and the price of item $i$ purchased from supplier $j$, respectively. Let $a_{i j}$ be the expenses which is supposed to be paid for item $i$ from supplier $j$. Let $s_{i}$ be the advantage of supplier $i$. Let $k, m$ and $n$ be the maximum possible price, the minimum expected quality and the minimum expected utility, respectively. Therefore, we have three goal constraints as follow,

$\sum_{i} \sum_{j} p_{i j} * x_{i j}+d^{-}-d^{+}=k$

$\sum_{i} \sum_{j} a_{i j} * x_{i j}+d^{-}-d^{+}=m$,

$\sum_{i} \sum_{j} s_{j} * x_{i j}+d^{-}-d^{+}=n$,

where Eq. (1) to Eq. (3) are the goal constraints associated with the price, the amount of expenses and the advantage of different suppliers, respectively. The necessary input parameters of Eq. (1) to Eq. (3) are obtained from the implementation of TOPSIS and VIKOR approaches explained earlier.

\subsubsection{Determining the parameters and structural limitations of the model}

In addition to soft constraints given in Eq. (1) to Eq. (3) we need to consider some hard constraints. The first hard constraint is associated with demand of all products as follows,

$\sum_{j} \mathrm{x}_{\mathrm{ij}}=D_{i}$

The second constraint is associated with the limitation on each supplier which is as follows,

$x_{i j} \leq C_{i j}$,

where $C_{i j}$ is the capacity of supplier $j$ for part $i$.

There are normally some constraints associated with our strategic policy to maintain a minimum level of purchase from each supplier.

$x_{i j} \geq v_{j} * \sum_{j} \mathrm{x}_{\mathrm{ij}}$

where $v_{j}$ is percentage of part $i$ assigned to supplier $j$. Finally, all variable must remain nonnegative, i.e., $x_{i j} \geq 0$ and $\quad$ Integer $\quad \forall_{i, j}$

\subsection{The efficient results}

The proposed model of this paper has been applied for the case study of our proposed model and the results using four MCDM techniques, with and without factor analysis, are summarized in Table 8.

\section{Table 8}

Results obtained from comparing model out puts to the present situation

\begin{tabular}{ll}
\hline Model 1 (using the results of TOPSIS technique) & $14 \%$ reduction in cost \\
& $25 \%$ increase in quality \\
Model 2 (using the results of VIKOR technique) & $4 \%$ reduction in acceptability \\
\hline Model 3 (using a combination of the results of TOPSIS and factor analysis & $2 \%$ increase in cost \\
techniques) & $39 \%$ increase in quality \\
\hline & $\begin{array}{l}3 \% \text { reduction in cost } \\
\text { Model } 4 \text { (using a combination of the results of VIKOR and factor analysis) }\end{array}$ \\
\hline
\end{tabular}


Considering the results, it's clear that model 4 fulfilled all the regarded targets. The model, which is based on obtained weights of VIKOR and factor analysis methods, could reduce the costs up to $9 \%$, and increase quality and perfection up to 38 and $3 / 2$ percent, respectively. In general, we can conclude that the considered model is an ideal model, which can support the experts to achieve their goals.

\section{Conclusion}

In this paper, we have presented an integrated model with the balanced score card framework for supplier selection strategy. The proposed model of this paper has gathered 161 important factors suggested in the literature and selected the six most important ones using different multi criteria techniques. We have also proposed a goal programming techniques with some hard constraints and implemented the mathematical model for real-world case study of auto industry. The proposed model has been solved in four different forms using TOPSIS, VIKOR and the combination of these 2 factors with factor analysis. The results indicated that a combination of VIKOR and factor analysis presented better results with $9 \%$ reduction in costs, $38 \%$ increase of quality, and $3.2 \%$ increase in acceptability.

\section{References}

Aissaoui, N., Haouari, M., \& Hassini, E. (2007). Supplier selection and order lot sizing modeling: A review. Computers \& Operations Research, 34(12), 3516-3540.

Anderson, H. V., Lawrie, G. \& Shulver, M. (2000). The balanced scorecard vs. the EFQM business excellence model - which is the better strategic management tool? 2GC Active Management, 1-15.

Decoene, V. \& Bruggeman, W. (2006). Strategic alignment and middle-level manager's motivation in a Balanced Scorecard setting. International journal of Operations \& Production Management, 26(4), 429-448.

Dulmin., R. \& Mininno, V. (2003), Supplier selection using a multi-criteria decision aid method. Journal of Purchasing \& Supply Management, 9, 177- 187.

Guneri, A. F., Yucel, A., \& Ayyildiz,G. (2009). An integrated fuzzy approach for supplier selection problem in SCM. Expert System with Applications, 36, 9223-9228.

Guo, X., Yuan, Z., \& Tian, B. (2009). Supplier selection based on hierarchical potential support vector machine. Expert Systems with Applications, 36, 6978-6985.

Ha, S. H., \& Krishnan, R. (2008). A hybrid approach to supplier selection for the maintenance of a competitive supply chain, Expert Systems with Applications, 34(2), 1303-1311.

Hsu, C. W., \& Hu, A. H. (2009). Applying hazardous substance management supplier selection using analytical network process, Journal of Cleaner Production, 17, 255-264.

Kaplan, R. S., \& Norton, D. P. (1996). The balanced scorecard translating strategy into action. Boston: Harvard Business School Press.

Kaplan, R. S., \& Norton, D. (1992). The balanced scorecard measures that drive performance. Harvard Business Review, 70(1), 71- 79.

Keskin, G.A., Ilhan, S. \& Ozkan, C. (2010). The Fuzzy ART algorithm: A categorization method for supplier evaluation and selection. Expert Systems with Applications, 37, 1235-1240.

Kline, P. (1993). An Easy Guide to Factor Analysis, Taylor and Francis Inc. ISBN: 0415094895.

Lam, K. C., Tao, R., Lam, M. C. K. (2010). A material supplier selection model for property developers using fuzzy principal component analysis. Automation in Construction, 19, 608-618.

Lee, A. H. I. (2009). A Fuzzy supplier selection model with the consideration of benefits, opportunities, cost and risk. Expert Systems with Applications, 36(2), 2879-2893.

Lin, C. W. R., \& Chen, H. Y. S. (2004). A fuzzy strategic alliance selection framework for supply chain partnering under limited evaluation resources. Computers in Industry, 55, 159-179. 
Luo, X., Wu, C., Rosenberg, D., \& Barnes, D. (2009). Supplier selection in agil supply selection: An information processing model and an illustration. Journal of Purchasing \& Supply Management, $15,249-262$.

Liao, C. N., \& Kao, H. P. (2010). Supplier selection model using Tagouchi loss function, analytical hierarchy process and multi-choice goal programming, Computers \& Industrial Engineering, 58, 571-577.

Marvin E, Quesada G, Mora Monge C A (2004). Determining the importance of the supplier selection process in manufacturing: a case study. International Journal of Physical Distribution \& Logistics Management, 34(6), 492-504.

Mikhailov, L. (2002). Fuzzy analytical approach to partnership selection information of virtual enterprises. Omega: The International Journal of Management Science, 30, 393-401.

Önüt, S., Soner Kara, S., \& Işik, E. (2009). Long term supplier selection using a combined Fuzzy MCDM approach: A case study for a telecommunication company. Expert System With applications, 36(2), 3887-3895.

Razmi, J., Jafari, M., Khakbaz, M. H. (2008). An integrated fuzzy group decision making/fuzzy linear programming (FGDMLP) framework for supplier evaluation and order allocation. International Journal of Advanced Manufacturing Technology, 43(5-6), 590-607.

Sawik, T. (2010). Single VS. Multiple objective supplier selection in make to order environment, Omega, 38(3-4), 203-212.

Shen, C. Y., \& Yu, K. T. (2009). Enhancing the efficacy of supplier selection decision making on the initial stage of new product development: A hybrid Fuzzy approach considering the strategic and operational factors simultaneously, Expert Systems with Applications, 36, 11271-11281.

Sim, K. L. \& Koh, H. C. (2001). Balanced Scorecard: A rising trend in strategic performance measurement. Measuring Business excellence, 5(2), 18-26.

Ustun, O., \& Demirtas, E. A. (2008). An integrated multi-objective decision making process multiperiod lot-sizing with supplier selection, Omega, 36, 509-521.

Wang, W. P. (2010). A Fuzzy linguistic computing approach to supplier selection, Applied Mathematical Modeling, 34, 3130-3141.

Wongrassamee, S., Gardiner, P. D. \& Simmons, J. E. L. (2003). Performance measurement tools, the Balanced Scorecard and EFQM Excellence model. Measuring Business Excellence, 7(1), 14-29.

Wu, W., Sukoco, B. M., Li, C. Y., \& Chen, S. H. (2009). An integrated multi-objective decisionmaking process for supplier selection with bundling problem, Expert Systems with Applications, $36(2), 2327-2337$.

Wu, D. (2009). Supplier selection: A hybrid model using DEA decision tree neural network, Expert Systems with Applications, 36(5), 9105-9112.

Yoon, K., \& Hwang, C. (1981). Multiple Attribute Decision Making Method and Applications. Berlin: Springer. 